\title{
A framework to measure microaggressions in the mathematics classroom
}

\section{Hazel J. McKenna ${ }^{1}$ (D) Kuo-Liang Chang $^{1} \mathbb{D} \cdot$ Thomas Mgonja $^{1} \mathbb{D}$}

Received: 21 November 2020 / Accepted: 24 March 2021 / Published online: 26 April 2021

(c) The Author(s) 2021

\begin{abstract}
Discriminatory treatment has been identified as one of the major factors that cause the mathematics achievement gap between White and many minority students, particularly, African Americans, Hispanics, and Native Americans. Culturally Responsive Teaching has been promoted as a means to reduce discrimination in the classroom. However, the appearance of neo-racism in the form of racial microaggressions suggests that Culturally Responsive Teaching may not be enough. Three personality types along with their traits have been identified as the source of racial microaggressions in social psychology. In this theoretical paper, we propose a framework to help researchers and teachers become aware of and identify microaggressions and their extent in a mathematics classroom. The framework is based on two defined types of microaggressions and three personality types that strongly predict discriminatory behaviors.
\end{abstract}

Keywords Microaggressions - Racial discrimination - Mathematics achievement gap · Equity

\section{Introduction}

Over the past two decades, there has been a nearly constant achievement gap in mathematics performance (e.g., NAEP 12th grade report, SAT scores) between White students and the minority groups of African Americans, Hispanics, and Native Americans in the United States. Researchers have identified several factors that have contributed to the cause of this achievement gap, including racial

Kuo-Liang Chang

kchang@uvu.edu

Hazel J. McKenna

Hazel.McKenna@uvu.edu

Thomas Mgonja

ThomasM@uvu.edu

1 Utah Valley University, Orem, USA 
discrimination from teachers and peers, biased curricula, lack of resources, the socioeconomic status (SES) of parents, and the cultural values that the students hold (Eccles et al. 2006; Lee, 2002; Lee and Bowen 2006; Levy et al. 2016; Pascoe and Smart Richman 2009; Stone and Han 2005; Williams 2011; Wong et al. 2003). In this paper, we focus on teachers' discrimination towards racially/ethnically and culturally different minority groups of students.

Culturally Responsive Teaching (CRT) has been proposed and promoted as a means to end racial and cultural inequalities in educational institutions and to close the achievement gap (Ladson-Billings 1992). The major goal of CRT is to help teachers build a culturally inclusive classroom by recognizing, appreciating, and integrating racial and cultural knowledge and values into their instruction and curriculum, to not only reduce discriminatory treatments, but also to promote academic success for minority students. However, compliance with CRT methods will not necessarily change teachers' deeply held beliefs and personalities, and teachers may unknowingly bring their mainstream, White-centered beliefs, and personalities into their classrooms in the form of microaggressions. Unlike traditional racism that is overt racial hatred and bigotry based on the concept of a hierarchy of races or support of segregation, racial microaggressions manifest in a subtler and race-less way, especially when a plausible non-racist excuse is available, such as human nature or common sense (Council of Europe, 2015; Lee and Rice 2007; Poteat and Spanierman, 2012; Schnake et al. 2006; Sue et al. 2007).

The literature of social psychology has identified the beliefs and traits of individuals with high Social Dominance Orientation (SDO), high Right-Wing Authoritarianism (RWA), and Color-Blind Racial Ideology (CBRI) as the source of racial microaggressions. To reduce racial discrimination in classrooms, we propose a framework to help researchers and teachers identify racial microaggressions and their extent within the context of a mathematics classroom, where teachers may or may not be aware of their discrimination. The two-dimensional framework is based on two types of microaggressions (i.e., insult, invalidation) and the three types of beliefs and personalities (i.e., high SDO, high RWA, and CBRI) that strongly predict racial discrimination behaviors.

\section{The nature of the mathematics achievement gap}

The National Assessment of Educational Progress (NAEP) tracks changes in students' mathematics test performance over time. NAEP data show that the $12^{\text {th }}$ grade Black-White achievement gap in mathematics has remained constant at 30/31 points (19\%) from 2005 through 2019 (National Center for Education Statistics 2019). Although the math achievement gap is largest for Black students, it also exists for American Indian/Alaskan Native students (23 points; 14\%) and Latin $x$ students (22 points; 14\%) compared to White students (see Fig. 1). The 2019 NAEP report also specified that only $8 \%$ of Black, $9 \%$ of American Indian/Alaskan Native, and $11 \%$ of Latinx 12th grade students were testing at or above proficiency in mathematics compared to $32 \%$ of their White counterparts and 52\% of their Asian counterparts (National Center for Education Statistics 2019). 


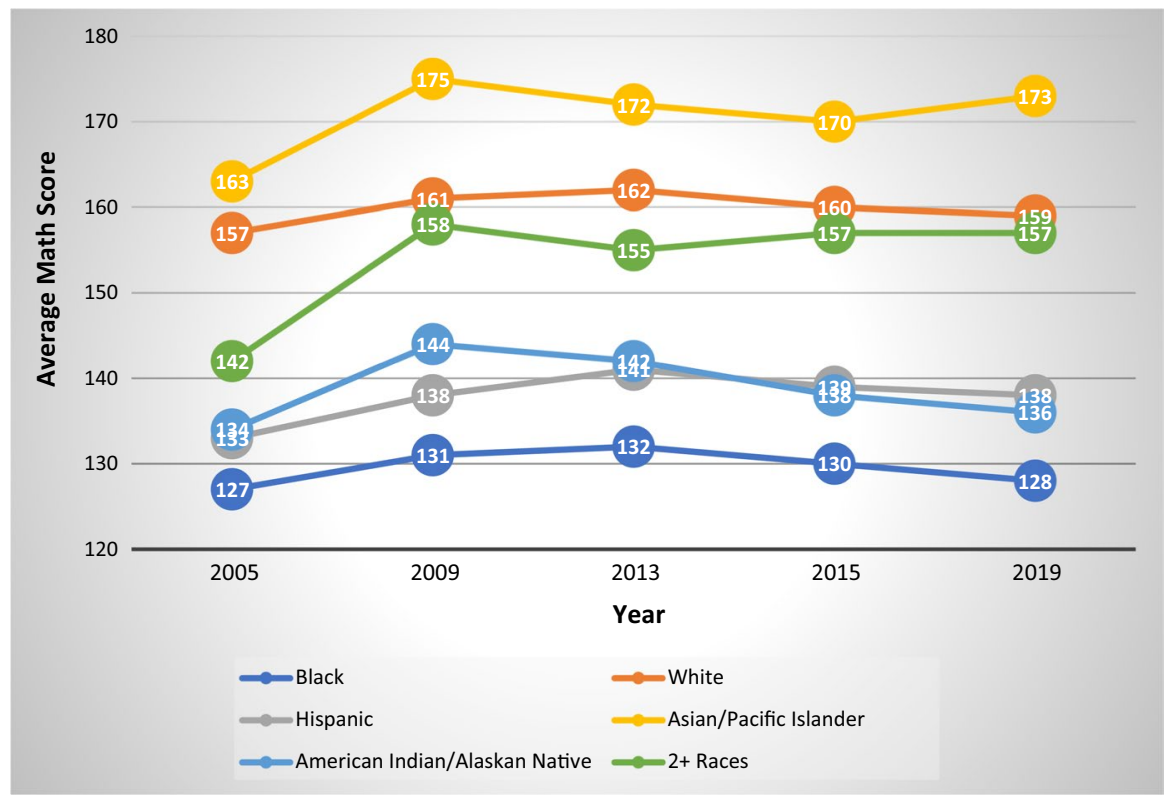

Fig. 1 Average NAEP scores by race for grade 12 mathematics for years 2005, 2009, 2013, 2015, and 2019 (National Center for Education Statistics 2019)

This persistent performance difference in mathematics is also observed on the Scholastic Aptitude Test (SAT) where the SAT performance gaps have persisted through 2019 despite SAT's efforts to modify the test (SAT 2019). To make matters worse, the math achievement gap has been increasing between high- and low-socioeconomic status (SES) students for the past 20 years (Paschall et al. 2018) due in part to increasing income segregation that has led to greater differentiation in school quality and schooling opportunities between the rich and the poor (Reardon 2011).

The pattern continues with the American College Testing (ACT) college readiness benchmarks in mathematics, where only $39 \%$ of ACT-tested high school students in 2019 were prepared for college with respect to mathematics. This lack of mathematical preparation was highly dependent on race: $68 \%$ of Asians; $48 \%$ of Whites; 23\% of Pacific Islanders; $25 \%$ of Hispanics; $14 \%$ of American Indians; and $12 \%$ of Blacks (ACT 2019) were ready for college mathematics. Identifying the cause of and reducing the mathematics achievement gap would go a long way in providing equity for minority students.

\section{Investigated causes and solutions of the achievement gap}

The process of identifying factors that cause the gap is complex. Studies have classified a range of reasons from social factors such as the widening socioeconomic gaps, home-based factors such as parental influences, and school-based factors such as resources and curriculum (Lee 2002; Lee and Bowen 2006). Federal policies such as 
the 2002 No Child Left Behind Act (NCLBA) followed by the 2015 Every Student Succeeds Act (ESSA) were enacted in an attempt to close the gap. Williams (2011) identified tracking, low teacher quality, non-standards-based instruction, racial stereotypes, and discrimination or biases among the causes of the performance disparity. Yet, despite identifying causes and implementing solutions, the performance gaps between White and Non-Asian minority students continue to exist.

Racism, whether overt or unintended, is a form of discrimination that negatively affects ethnic minority students' concentration and motivation, and therefore impairs learning (Levy et al. 2016). Levy et al. (2016) assert that the stress of racial discrimination may play a key role in explaining the persistent nature of achievement gaps between ethnic minorities and their White counterparts. Even perceptions of discrimination from teachers are associated with lower grades, motivation, and less persistence when ethnic minority students are faced with academic challenges (Alfaro et al. 2009; Eccles et al. 2006; Stone and Han 2005). Wong et al. (2003) showed that racial discrimination from a minority student's teacher or classmate was related with the student's academic attitudes that school was less important, especially for their future, and it was able to predict declines in grades. In addition, perceptions of racial discrimination were related to lower beliefs in students' own academic competence. With the many effects of racial discrimination that are associated with lower levels of academic performance, it is imperative to investigate methods that could potentially mitigate such effects.

\section{Culturally responsive teaching}

Ladson-Billings (1992) coined the phrase, 'culturally relevant teaching' to describe a 'pedagogy of opposition' that was more than just good teaching, but specifically, committed to collective, not merely individual, empowerment. For teaching to be considered culturally responsive, it must meet three criteria: (a) Students must experience academic success; (b) students must develop and/or maintain cultural competence; and (c) students must develop a critical consciousness through which they challenge the status quo of the current social order (Ladson-Billings 1992). CRT was an effort to address the symptoms (educational gaps, dropout rates, and low test-scores of underprivileged students and students of color) indicative of cultural and racial inequality in the US school system.

Gay (2002) defined CRT as using the cultural characteristics, experiences, and perspectives of ethnically diverse students as a means to teaching them more effectively. CRT has also been defined as "the teacher's ability to integrate content, facilitate knowledge construction, reduce prejudice, model social justice, and develop students academically to meet the needs of all learners" (Herandez et al. 2013, p. 369). Whatever the working definition, CRT requires a mindful practice and researchbased teaching methods that bring about the inclusion of other races and cultures.

Numerous studies provide evidence that CRT promotes academic achievement and engagement (see, e.g., Christianakis 2011; Ensign 2003; Rodriguez et al. 2004), as well as a sense of social consciousness and critique (see, e.g., Morrell and Duncan-Andrade 2002; Stovall 2006). In addition, CRT can promote positive ethnic/ 
racial identity and cultural affirmation, competence and exchange, and positive attitudes towards others (see, e.g., Dessel et al. 2006; Sleeter 2012). Unfortunately, most of the studies on the effectiveness of CRT are qualitative case studies conducted in classrooms that exemplify CRT and focus on a homogeneous, usually Black or Latinx, carefully selected set of K-12 students, and which, therefore, cannot definitively point to CRT as the sole cause of an improvement in students' achievement (Aronson and Laughter 2015; Morrison et al. 2008). However, Byrd (2016) found support for the effectiveness of CRT by surveying a diverse sample of sixth- through twelfth-grade students from across the US in everyday classrooms. She was able to show that CRT is "an important method for promoting achievement and positive identities for students of all races" (Byrd 2016, p. 7). Unfortunately, CRT is often simplified, stereotyped, and used only in occasional group work (Byrd 2016; Sleeter 2012).

Despite efforts to develop CRT in K-12 mathematics, there is still a huge achievement gap in mathematics between different racial and culturally diverse groups (National Center for Education Statistics 2019). Granted, CRT is probably not being used in all classrooms, and this may account for some of the reasons that the mathematics achievement gap still exists, but there must be other factors.

\section{Culturally responsive teaching is not enough: microaggressions from teachers}

The implementation of Culturally Responsive Teaching may not be enough to eliminate all bias, inequalities, or discrimination in a classroom, as it may not be sufficient to fundamentally change teachers' verbal and behavioral practice. By its definition, CRT is prescriptive, and it should not be too difficult to equip teachers with knowledge (e.g., culturally diverse knowledge base); culturally relevant curricula; instructional methods (e.g., recognize, respect, and appreciate different cultural values, connect to students' lives and communities); and school policy and procedure (e.g., equitable and social justice practice in the school and classroom context) to change teachers classroom practice and management. They can go through the motions and teach using CRT methods, but how do their biases, assumptions, and lack of true belief in the students show up in the classroom? Is it possible that teachers' personalities and beliefs show up as microaggressions towards students that the teachers themselves may be completely unaware of, but students see and feel? These microaggressions could define the classroom environment. After all, every educator, regardless of how much they have philosophized over their own race and culture, takes their beliefs, biases, and assumptions into the classroom. It is difficult to change the ingrained beliefs and personality of a teacher who comes from mainstream society; a society that is predominately white and enjoys the privileges of being white. Moreover, changes made in a school context do not imply changes in a teacher's personal life, neighborhood, community, social media, political party, or even religious practices. People will still believe and defend what they want to believe, and act accordingly in their personal life. White (2012) contends that teachers avoid exploring their own personalities, and often deny pervasive educational 
inequalities. This denial shows up when teachers need to "defend dominant social values from which they have personally benefitted" (White 2012, p. 12) and when they have a "defensive reaction to challenges posed to their core beliefs and sense of self or individual identity" (White 2012, p. 13).

Such difficult, or perhaps impossible, to change beliefs and personalities developed over time within a mainstream culture can penetrate a classroom, even when CRT is being implemented, and manifest as racial microaggressions.

\section{The definition and effect of racial microaggressions}

Racial microaggressions have been defined as "brief and commonplace daily verbal, behavioral and environmental indignities, whether intentional or unintentional, that communicate hostile, derogatory, or negative racial slights and insults to the target person or group" (Sue et al. 2007, p. 273). Racial microaggressions communicate the prejudiced beliefs and personalities of the individuals enacting them to people of color and, whether intentional or unintentional, they are hostile, derogatory, denigrating, insulting, and hurtful (Allen 2012; Sue et al. 2007). According to Allen (2012), they "are felt through environmental cues as well as verbal and nonverbal hidden messages that serve to invalidate one's experiential reality and perpetuate feelings of inferiority" (p. 175). For example, in a classroom context, a teacher may seldom or never make eye contact with minority students, or the teacher may treat students who miss class or homework assignments differently depending on their race, simply due to the teacher's personal beliefs about such students. Unlike traditional racism that is overt racial hatred and bigotry based on the concept of a hierarchy of races or support of segregation, microaggressions manifest in a subtler and race-less way, especially when a plausible non-racist excuse is available, such as human nature or common sense (Council of Europe 2015; Lee and Rice 2007, p. 389; Poteat and Spanierman 2012; Schnake et al. 2006; Sue et al. 2007).

Sue et al. (2007) proposed three basic categories of microaggressions: assault, insult, and invalidation. A microassault is conscious and deliberate, old-fashioned racism enacted on individuals in the form of racist slurs or racist attacks (e.g., displaying a swastika; using racial epithets). The assault microaggression is not considered in this paper as such overt racism would never be tolerated in a mathematics classroom. A microinsult is a usually intentional, subtle snub that conveys rudeness and insensitivity, and is used to demean a person's racial heritage or identity (e.g., asking a Black person how they were able to get into a mostly White university). A microinvalidation is usually an unintentional comment or behavior that invalidates a person's thoughts, feelings, or experiences (e.g., assuming an Asian American speaks Chinese, or complementing them on their English).

The effects of racial microaggressions over time are not only comprehensive, but also deeply affect an individual's psychological and social development. Racial microaggressions psychologically damage students' mental health, showing up as depression, anxiety, perceived stress, frustration, resentment, shame, embarrassment, feeling powerless or invisible, self-doubt, and chip away at students' self-concept and positive racial identity development (Allen et al. 2013; Ong et al. 2013; 
Solorzano et al. 2000; Sue et al. 2008; Torres et al. 2010; Torres-Harding and Turner 2015). By the time students get to college, it is not rare to see minority students being quiet, afraid of speaking in public, isolated, or sometimes even dropping a class due to various verbal or behavioral microaggressions experienced from their teachers or other students. As a result, it lowers students' work productivity and problem-solving abilities (Sue et al. 2009).

\section{Microaggressions from teachers}

Interactions between students and teachers define the classroom environment, and what teachers believe about their students can lead to microaggressions. Deficit thinking is the cause of most microaggressions from teachers (Ford et al. 2006; Grantham and Ford 2003). As defined by Ford et al. (2006) in Allen et al. (2013), "deficit thinking is the negative, stereotypical, and prejudicial beliefs one holds about diverse groups," and "teachers often interpret differences as deficits, dysfunctions, and disadvantages in students and their cultures" (Allen et al. 2013, p. 122). A prevalent result of deficit thinking is differential treatment in classrooms based on the assumptions of intelligence or the life environment of students (Allen et al. 2013).

It is not easy to eliminate microaggressions, as it takes time and effort to change beliefs or personality and it is an individual's right to decide whether they even want to change. As a result, many teachers use their power to identify what is racism and what is not racism based on their own beliefs and personalities. They also use their power to challenge students' rights and abilities of calling out racism that affects the students' own lives (Call-Cummings and Martinez 2017). Then again, some teachers take passive attitudes to avoid or ignore racial issues. Sue et al. (2009) indicate that some teachers "take a passive approach (i.e., let the class take over the discussion), disengage (i.e., don't initiate, go with superficial responses, and dismiss the importance of the topic), become emotional (i.e., "get mad at what is being said [directed toward the student of color]"), or simply ignore the dialogue altogether (i.e., switch topics)" (p. 188).

With the unbalanced power structure between students and teachers, students have developed passive and self-preservation attitudes in responding to microaggressions from teachers. Students start to think that their racist teachers cannot and will not change, and because of this start to believe it is their responsibility to fix microaggressions from their teachers (Call-Cummings and Martinez 2017, p. 568).

In summary, the source of the racial microaggressions is rooted in the difficult to change beliefs and personalities of teachers, formed and formatted, and continuing to form, in their mainstream neighborhoods and society. Although an individual's choice of living values and style is a human right and should be protected, more efforts are needed to encourage individuals to assimilate themselves into different racial groups to experience different cultures. As Henfield and Washington (2012) indicated, "Perhaps the greatest concern is that many White teachers have limited personal and professional encounters with individuals who are racially, ethnically, linguistically and culturally different from themselves...this unfamiliarity with 
diverse students can leave teachers ill-prepared to function effectively in multiracial schools" (p. 148).

\section{The roots of microaggressions}

Psychology research has emphasized two major lines of explanation of why some people are more prejudiced than others-either stable factors within the individual (i.e., people's internal attributes or personality characteristics) or factors linked to people's social identity, social self-characterization, or social position. There is a strong argument that prejudice is basically a personality trait (Altemeyer 1996; McFarland et al. 1993).

Two major theories have been advanced to explain prejudice within the personality approach: authoritarian personality theory (Adorno et al. 1950) and right-wing authoritarianism (RWA; Altemeyer 1981, 1998), and the theory of social dominance orientation (SDO; Pratto et al. 1994; Sidanius and Pratto 1999).

\section{RWA and SDO}

RWA is a measurable personality trait that is based on conventionalism, authoritarian submission, and authoritarian aggression (Altemeyer 1981). Thus, high-RWA people tend to favor traditional values and adhere to social norms, are submissive towards authority figures they see as established and legitimate, highly ethnocentric, and hostile and punitive towards outgroups, those believed to be categorized as deviant by established authorities (Altemeyer 1981, 1998). They value uniformity and are in favor of using group authority, including coercion, to achieve it (Stenner 2009). A large body of research attests that the RWA Scale is a powerful predictor of prejudice and negative attitudes towards immigrants, different races, women, homosexuals, and different religions (see, e.g., Altemeyer 1998; Lippa and Arad 1999; McFarland et al. 1993; Reynolds et al. 2001; Whitley 1999; Whitley and Ægisdottir, 2000; Whitley and Lee 2000). People with high RWA show prejudice as they tend to view outgroup members as a threat to the social order and stability of their own group.

In contrast, SDO is a personality trait that predicts social and political attitudes and is conceptualized as a measure of individual differences in levels of group-based discrimination (Sidanius and Pratto 2001). That is, it is a measure of a person's preference for hierarchy within any social system and the domination over lower-status groups. SDO is the individual attitudinal aspect of Social Dominance Theory proposed by Sidanius and Pratto (2001) and is influenced by group status, socialization, and temperament. In turn, it influences support for hierarchy-enhancing and hierarchy-attenuating 'legitimizing myths,' such as values, attitudes, beliefs, causal attributions, and ideologies, that in turn justify institutions and practices that either enhance or attenuate group hierarchy. High SDO people tend to support and encourage intergroup hierarchies and rank social groups in an unequal, superior-inferior hierarchy, where some groups are in positions of dominance and power over others. 
Typically, high SDO people are dominant, driven, and seekers of power, and believe in a dog-eat-dog world where each individual has to maximize his or her personal benefits (Levin et al. 2002). High SDO individuals have reported greater perceived competition with other groups and greater dehumanization of immigrants (Hodson and Costello 2007). In comparison, low SDO individuals reflect egalitarianism and altruism; independence and autonomy (Duckitt et al. 2002). Research attests to SDO's ability to predict various types of prejudice and correlates strongly with authoritarian and racist beliefs as well as sexism, homophobia, ethnocentrism, and generalized prejudice (see, e.g., Akrami et al. 2000; Duriez and Van Heil 2002; Ekehammar et al. 2004; Lippa and Arad 1999; Pratto et al. 1994; Sidanius et al. 1994, 1996; Whitley 1999; Whitley and Ægisdottir 2000; Whitley and Lee 2000; Van Hiel and Mervielde 2002).

Individually, SDO and RWA are essential predictors of prejudice in general and racism in particular (Altemeyer 1998; Duckitt et al. 2001; McFarland 2001) and appear to be inherited across generations and through socialization (see, e.g., Duriez et al. 2008; Duriez and Soenens 2009). A study by Poteat and Spanierman (2012) shows that SDO beliefs predict higher modern racism attitudes. The association between SDO and prejudice occurs almost entirely independently of RWA, and vice versa. Yet, SDO and RWA reflect additive processes (Sibley et al. 2006). This means that people who exhibit high scores on SDO and on RWA have higher levels of prejudice than people who score high on just one of these two scales.

SDO and RWA have some conceptual differences (Altemeyer 1998; Duriez and Van Hiel 2002; Heaven and Connors 2001; Whitley 1999): (a) Whereas SDO focuses on intergroup dominance, RWA is generally intragroup; (b) high-SDO people do not submit to others the way high-RWA people tend to do; (c) people high on the RWA scale tend to be religious; people high on the SDO scale do not; (d) highRWA people tend to need structure, conformity of values, and tradition, whereas high-SDO people do not; (e) high-RWA correlates with values of security, whereas high-SDO does not.

\section{Color-blind racial ideology}

Whereas RWA and SDO are among the strongest predictors of racial prejudice (Sibley \& Duckitt, 2008), color-blind racial ideology (CBRI) - the denial, distortion, or minimization of racism-is considered the dominant racial ideology of the postcivil rights era (Neville 2009; Neville et al. 2000). Many Whites view color-blind racial beliefs as fair, benign, and desirable, but they do not recognize their negative implications (Bonilla-Silva 2003; Neville et al. 2001; Rains 1998). CBRI beliefs include the attitude that race should not matter, and that achievements should be based on merit. Yet, unawareness of White privilege and institutional racism leads to maintaining the status quo of racial inequalities such as wealth/income, education, housing, and healthcare (Bonilla-Silva 2003; Thompson and Neville 1999).

In addition, CBRI predicts modern racism attitudes. The difference between CBRI and modern racism is that CBRI focuses on institutions (e.g., school systems), whereas modern racism focuses on attitudes directed towards racial minorities (e.g., 
microaggressions). CBRI reflects only the belief that race does not and should not matter in society without ascribing particular attitudes towards racial minority individuals, as do modern racism attitudes (Neville et al. 2000; Park and Judd 2005; Plaut et al. 2009).

\section{Psychological profiles in education}

When it comes to education, high RWA among students, faculty, or staff may have important implications for intergroup relations, especially on campuses with a homogeneous student population. For example, on a predominately White campus, high-RWA individuals may expect racial minorities to conform to campus norms that reflect White dominant values. High-RWA individuals may also have negative attitudes towards multicultural events. Racial minority students who discuss their culture or have opinions that are different from the norm may be targeted by highRWA individuals. These high-RWA individuals could be aggressive towards minority students in classroom discussions and could shut down their voices and opinions. High-RWA individuals could prove to be unbearable for minority students and contribute to an unwelcome campus climate.

Students with high SDO, on the other hand, may perceive that they are in competition with minority students even while believing that such students are inferior to them. High SDO students may regard minority students as a threat to them, which could lead them to adopt stronger negative attitudes towards minorities (BonillaSilva 2003). High SDO teachers could treat minority students differently than White students, considering them second class citizens unworthy of their time or attention or be punitive towards them for not acting like the norm.

CBRI focuses on the educational system, including classroom management. Although the concept of a teacher being color-blind and treating all students the same may sound like a reasonable thing to do, the unintended consequence when color-blindness is endorsed on a school campus is that White privilege is ignored, which perpetuates the status quo of racial inequalities. This may inadvertently lead to individuals adopting color-blind racial beliefs. Such individuals may hold stronger negative attitudes towards racial minorities who point out continued racial disparities because this threatens their belief system of a fair and just society (Neville et al. 2000, 2001).

\section{The framework for the mathematics classroom}

The three roots of microaggressions (RWA, SDO, CBRI) together with the two types of microaggressions (microinvalidation and microinsult) form a three-by-two framework (See Table 1) for the identification and analysis of microaggressions in the mathematics classroom. This framework may be used by mathematics education 
Table 1 The framework

\begin{tabular}{lll}
\hline Roots & Microinvalidation & Microinsult \\
\hline Right-wing authoritarianism (RWA) & Classroom context & Classroom context \\
Social dominance orientation (SDO) & Classroom context & Classroom context \\
Color-blind racial ideology (CBRI) & Classroom context & Classroom context \\
\hline
\end{tabular}

researchers and educators to categorize, analyze, and assess microaggressions in the classroom.

To help identify and measure microaggressions and their extent within teacher-student interactions, traits of the three roots (See Table 2) are added to the framework.

To help implement the framework, discriminatory beliefs and/or practices that have been discussed in the mathematics education literature or observed in mathematics classrooms are further added to the framework with respect to the traits of each root (See Table 3). This may help operationalize the framework. It is important to note that discriminations in a mathematics classroom are not limited to those listed in the framework. The listed discriminations will be explained later through examples.

Within the extent of microaggressions (i.e., microinvalidation and microinsult), the framework is then organized by codes (See Table 4). The letter "a" stands for microinvalidation, and the letter " $b$ " stands for microinsult.

Table 2 Traits of the three roots

\begin{tabular}{ll}
\hline Roots & Traits \\
\hline Right-wing authoritarianism (RWA) & Conventionalism \\
Social dominance orientation (SDO) & Authoritarianism \\
& Hierarchical social order \\
Color-blind racial ideology (CBRI) & Domination over lower-status groups \\
\hline
\end{tabular}

Table 3 Traits and discrimination items

\begin{tabular}{|c|c|c|}
\hline Personality and ideology & Traits & Discriminations \\
\hline \multirow[t]{2}{*}{$\begin{array}{l}\text { Right-wing authoritarianism } \\
\text { (RWA) }\end{array}$} & Conventionalism (V) & $\begin{array}{l}\text { European centered mathematics (E) } \\
\text { Deficit thinking (D) }\end{array}$ \\
\hline & Authoritarianism (A) & $\begin{array}{l}\text { Textbook authority }(\mathrm{X}) \\
\text { Teacher authority }(\mathrm{T}) \\
\text { Mathematician authority (M) }\end{array}$ \\
\hline \multirow{2}{*}{$\begin{array}{l}\text { Social dominance orientation } \\
\text { (SDO) }\end{array}$} & Hierarchical social order $(\mathrm{H})$ & Classification of people $(\mathrm{P})$ \\
\hline & $\begin{array}{l}\text { Domination over } \\
\text { Lower-status groups (D) }\end{array}$ & $\begin{array}{l}\text { Hostile competitive environment } \\
\text { (C) }\end{array}$ \\
\hline Color-blind racial ideology (CBRI) & Racial differences ignored (I) & \\
\hline
\end{tabular}




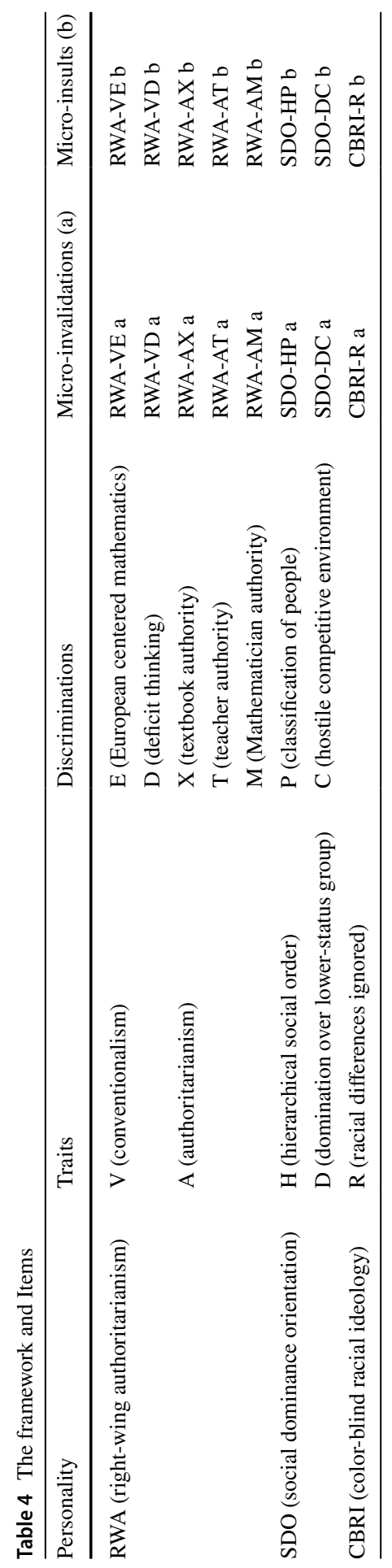


High-RWA individuals favor conservative and traditional values that can manifest as deficit thinking about outgroups. An outgroup is any group of people who do not fall into the mainstream, majority category (e.g., race, gender, sexual orientation, culture, ability, SES). A high-RWA math teacher may believe that outgroup students cannot do math because of their race or culture or gender or some combination of these, and this belief leads to microaggressions from the teacher to these outgroup students. As an example, according to the framework, a mathematics teacher who holds the conventionally conservative and traditional belief that mathematics means European mathematics may impose microaggressions on their students by invalidating outgroup students (e.g., students from the Middle East or Asian students) by ignoring or minimizing the contributions of mathematicians from their cultures (RWA-VE a). A more aggressive approach could be a microinsult where the teacher points out to the outgroup students that their cultures lack mathematics, and they need to learn mathematics from the western perspective (RWA-VE b). Likewise, a mathematics teacher who favors tradition and perceived authorities may treat published mathematics textbooks as the authority of the most correct, efficient, or effective methods for solving problems. The teacher may invalidate students' work by ignoring or minimizing their solution methods because the methods are different from methods described in the textbook (RWA-AX a). A more aggressive approach could be a microinsult where the teacher "corrects" a student's solution method to mimic the method used in the textbook, even though the student's solution method is also valid and may even be superior due to being more effective and efficient (RWAAX b).

When it comes to teachers with high SDO, there will be a preference for hierarchy, which could lead to a classification of students based on the teachers' preconceived ideas of the hierarchy of an outgroup. A high SDO teacher may avoid interacting with or ignore students considered to be in a hierarchically lower outgroup or may do the opposite and intentionally draw unwanted attention to such students. For example, according to the framework, a mathematics teacher who likes to classify students based on their performance may impose microaggressions on students. The teacher may invalidate low-performance students by ignoring them or treating their questions or requests with little thought (e.g., not extending homework deadlines or allowing them to make up missing assignments) (SDO-HP a). A more aggressive treatment (i.e., a microinsult) could be that the teacher judges the student's lifestyle or personality (e.g., lazy, stupid). Another possibility could be that the teacher decries an Asian student because he is not good at math (SDO-HP b). Likewise, a mathematics teacher who believes in competition that comes with punishment for losers may easily impose microaggressions on the students. The teacher may do the same microinvalidation of ignoring or carelessly treating a student who has poor performance in mathematics (SDO-DC a). A microinsult the teacher may make is to punish the student by taking away privileges (e.g., not allowing them to make up assignments) or imposing a punishment (e.g., asking the student to solve a problem in front of the whole class or requiring them to complete extra assignments) (SDO$\mathrm{DC}$ b).

A color-blind teacher, in an effort to treat all students the same, may inadvertently impose microaggressions on students. The teacher may make the microinvalidation 
by avoiding or ignoring students' cultural/racial needs, for example, by not allowing any headwear to be worn in the classroom, or by scheduling tests on religious or cultural holidays (CBRI-R a). A color-blind teacher, who ignores racial differences and treats all students the same, may be completely unaware that assigning her students homework that requires a computer and Internet access to complete is a microinsult when he/she assumes that all families can afford computers and Internet access (CBRI-R b).

\section{Pilot study}

A pilot study was conducted to evaluate whether the proposed framework is operational. By "operational," we mean firstly that the instrument items (i.e., survey questions) are easily constructed using the framework, and secondly that microaggressions in the mathematics classroom are identified through the items. We also hope that the items will differentiate between the experiences with microaggressions of white students and students of color (as well as other subpopulations such as gender, students who identify as LGBTQ+, etc.). However, this differentiation will require a much larger sample size. The current pilot study $(n=35)$ may not be appropriate to answer this question.

A survey of 21 questions was developed based on the framework. The number of questions for each category is listed in Table 5. The 21 questions can be found in Appendix A. All 21 of the questions ask about students' previous mathematics classroom experiences (in college or high school). Each question is associated with a 4-point Likert scale and another option of "I don't understand the question." The 4-point Likert scale was used so that students had to make a choice that the microaggression either occurred or did not occur; neutrality was removed from the equation. The four levels are "Strongly Agree," "Agree," "Disagree," and "Strongly Disagree." The levels "Strongly Agree" and "Agree" indicate that microaggressions were experienced in past mathematics classrooms. The levels "Strongly Disagree" and

Table 5 The framework and survey questions

\begin{tabular}{|c|c|c|c|}
\hline Personality & Traits & Discriminations & Questions \\
\hline \multirow[t]{5}{*}{ Right-wing authoritarianism } & \multirow[t]{2}{*}{ Conventionalism } & $\begin{array}{l}\text { European centered math- } \\
\text { ematics }\end{array}$ & 5,6 \\
\hline & & Deficit thinking & $1,2,3,4$ \\
\hline & \multirow[t]{3}{*}{ Authoritarianism } & Textbook authority & $7,8,9$ \\
\hline & & Teacher authority & 10,11 \\
\hline & & Mathematician authority & 12,13 \\
\hline \multirow[t]{2}{*}{ Social dominance orientation } & Hierarchical social order & Classification of people & $14,15,16$ \\
\hline & $\begin{array}{l}\text { Domination over lower-status } \\
\text { group }\end{array}$ & $\begin{array}{l}\text { Hostile competitive environ- } \\
\text { ment }\end{array}$ & $17,18,19$ \\
\hline Color-blind racial ideology & Racial differences ignored & & 20,21 \\
\hline
\end{tabular}


"Disagree" indicate that microaggressions were not experienced in past mathematics classrooms.

The survey was distributed to college students at a large state university in the intermountain west of the United States. Thirty-six students participated in the study, with 34 students completing the survey. One student quit right after consenting to take the survey. Another student answered only the first 8 questions.

The pilot study confirms that the framework is operational. First, three researchers (the authors) were able to develop survey items for each category of the framework in a two-hour meeting. Second, the survey results indicate that students experienced microaggressions in mathematics classrooms. Seven out of 21 questions (1/3 of the questions) indicate that at least $50 \%$ of the participants experienced microaggressions in mathematics classrooms. Twelve out of 21 questions (more than half of the questions) indicate that at least $25 \%$ of the participants experienced microaggressions in mathematics classrooms. Lastly, each of the 21 questions indicates that at least $10 \%$ of the participants experienced microaggressions in mathematics classrooms (see Table 6). Therefore, the survey questions generated using the framework can identify microaggressions students experienced in mathematics classrooms.

In addition, the pilot indicates that students of color may have different experiences with microaggressions than white students. However, with such a small sample size $(n=35)$ a full-scale study with a much larger sample size will be required to confirm the differences. According to the survey results, 11 students of color and 24 white students participated in the pilot survey. For questions 5, 6, 7, and 8, the percentage of students who agreed or strongly agreed with the item in either the students of color group or the white students' group is about twice as many as the other group (See Table 7), which indicates the possibility of differences between the two groups of students.

\section{Summary}

The mathematics achievement gap between White and many minority students exists primarily because of racial discrimination. Culturally Responsive Teaching (CRT) has been proposed and promoted as a means to end racial discrimination

Table 6 Percentages of agree versus disagree

\begin{tabular}{lllllllllll}
\hline Question & Q1 & Q2 & Q3 & Q4 & Q5 & Q6 & Q7 & Q8 & Q9 & Q10 \\
\hline Strongly agree or agree (\%) & 23 & 29 & 40 & 31 & 17 & 14 & $\mathbf{5 1}$ & $\mathbf{6 0}$ & $\mathbf{5 0}$ & $\mathbf{5 0}$ \\
Strongly disagree or disagree (\%) & 77 & 71 & 60 & 66 & 77 & 77 & 46 & 40 & 50 & 47 \\
\hline Q11 & Q12 & Q13 & Q14 & Q15 & Q16 & Q17 & Q18 & Q19 & Q20 & Q21 \\
\hline $\mathbf{5 3}$ & 26 & 38 & 24 & $\mathbf{5 3}$ & 21 & $\mathbf{5 6}$ & 26 & 15 & 29 & 18 \\
47 & 74 & 59 & 76 & 47 & 79 & 44 & 74 & 74 & 53 & 82 \\
\hline
\end{tabular}

The bold value highlights the survey items that indicate that at least $50 \%$ of the participants experienced microaggressions in mathematics classrooms 
Table 7 Percentages of agree between Non-White and White students

\begin{tabular}{lcccccccccc}
\hline Question & Q1 & Q2 & Q3 & Q4 & Q5 & Q6 & Q7 & Q8 & Q9 & Q10 \\
\hline $\begin{array}{l}\text { Students of color } \\
\text { Strongly agree or agree (\%) }\end{array}$ & 27 & 27 & 45 & 27 & $\mathbf{2 7}$ & $\mathbf{9}$ & $\mathbf{2 7}$ & $\mathbf{3 6}$ & 40 & 40 \\
$\begin{array}{l}\text { White students } \\
\text { strongly agree or agree (\%) }\end{array}$ & 21 & 29 & 38 & 33 & $\mathbf{1 3}$ & $\mathbf{1 7}$ & $\mathbf{6 3}$ & $\mathbf{7 1}$ & 54 & 54 \\
\hline Q11 & Q12 & Q13 & Q14 & Q15 & Q16 & Q17 & Q18 & Q19 & Q20 & Q21 \\
\hline 50 & 30 & 40 & 30 & 40 & 20 & 50 & 30 & 10 & 30 & 20 \\
54 & 25 & 38 & 21 & 58 & 21 & 58 & 25 & 17 & 29 & 17 \\
\hline
\end{tabular}

The bold value highlights the survey items that indicate the percentage of students who agreed or strongly agreed with the item in either the students of color group or the white students' group is about twice as many as the other group

in the classroom and to help close the achievement gap. However, neo-racism is appearing in the form of racial microaggressions, showing that CRT may not be enough. Social psychology has identified some beliefs and personalities (e.g., high SDO, high RWA, and CBRI) as the source of racial microaggressions. To help reduce or end racial discrimination in classrooms, we propose a framework to help identify the microaggressions teachers may use towards their students, whether intentional or not. The framework is based on two defined types of microaggressions (insult and invalidation), three types of belief and personality (SDO, RWA, and CBRI) that strongly predict racial discrimination behaviors, and the interactions between teachers and students in a mathematics classroom. The pilot study confirms that the framework is operational. The authors were able to develop 21 survey questions using the framework and the survey results indicate that students experienced microaggressions in mathematics classrooms.

This framework can be used to identify specific student-teacher interactions. We added examples of such interactions to the framework to help inform the reader of its possible use. Further research in this area could lead to a scale that could be used to measure the type and extent of microaggressions that occur in a mathematics classroom. Making teachers and prospective teachers aware of such microaggressions may improve student-teacher interactions and reduce the neoracism in our classrooms.

Unless we quickly close the race-, ethnicity-, and income-based mathematics achievement gaps, we are at risk of producing an even more unequal, economically, and racially polarized society. The theoretical framework we propose is a starting point to identify neo-racism in the classroom in the form of microaggressions. 


\section{Appendix A}

\section{Survey questions}

\section{RWA-V-D}

1. I had a math teacher who made assumptions about students' math ability because of their background (e.g., ethnicity, race, gender, sexual orientation, nationality).

2. I had a math teacher who made assumptions about my math ability because of my background (e.g., ethnicity, race, gender, sexual orientation, nationality).

3. I had a math teacher who made me feel uncomfortable asking questions.

4. I had a math teacher who seldom answered my questions.

\section{RWA-V-E}

5. I had a math teacher who only represented white American culture in the math my teacher presented.

6. I had a math teacher who only mentioned math contributions by Europeans.

\section{RWA-A-X}

7. I had a math teacher who told students their solutions were wrong because they used different methods to solve problems than the textbook.

8. I had a math teacher who only followed what the textbook said. Alternative methods or different ways of solving a problem were not taught or discussed.

9. I had a math teacher who believed that the answer in the textbook was correct even when no one in the class got the same answer.

\section{RWA-A-T}

10. I had a math teacher who seldom listened to students' perspectives. The teacher mainly focused on teaching their own methods.

11. I had a math teacher who demanded that we do mathematics their way.

\section{RWA-A-M}

12. I had a math teacher who made rude comments when we did not think or reason like a mathematician.

13. I had a math teacher who insisted we complete problems the way mathematicians would.

SDO-H-P 
14. I had a math teacher who classified students as good or bad based on their background (e.g., ethnicity, race, gender, sexual orientation, nationality).

15. I had a math teacher who treated students who were good in math better than those who were not good in math.

16. I had a math teacher who treated me poorly because of my background (e.g., ethnicity, race, gender, sexual orientation, nationality).

SDO-D-C

17. I had a math teacher who rewarded those who were good in mathematics.

18. I had a math teacher who created an unpleasant environment where we had to compete against each other.

19. I had a teacher who gave us grades based on our performance rank in the class (e.g., the top $10 \%$ get an A while the bottom $10 \%$ get an E; exam scores are curved).

\section{CBRI-R}

20. I had a math teacher who ignored differences in students' ethnic backgrounds and how the differences can be valuable to the class.

21. I had a math teacher who ignored students' cultural/racial needs (e.g., speaking slower for non-native English speakers; recognizing that Islamic students are fasting during Ramadan; recognizing that not all students are familiar with playing cards).

Data availability The datasets generated during and/or analyzed during the current study are available from the corresponding author on reasonable request.

\section{Compliance with ethical standards}

Conflict of interest The authors declare that they have no conflict of interest.

Open Access This article is licensed under a Creative Commons Attribution 4.0 International License, which permits use, sharing, adaptation, distribution and reproduction in any medium or format, as long as you give appropriate credit to the original author(s) and the source, provide a link to the Creative Commons licence, and indicate if changes were made. The images or other third party material in this article are included in the article's Creative Commons licence, unless indicated otherwise in a credit line to the material. If material is not included in the article's Creative Commons licence and your intended use is not permitted by statutory regulation or exceeds the permitted use, you will need to obtain permission directly from the copyright holder. To view a copy of this licence, visit http://creativecommons.org/licen ses/by/4.0/.

\section{References}

ACT (2019) The condition of college and career readiness 2019. https://www.act.org/content/dam/act/ unsecured/documents/cccr-2019/National-CCCR-2019.pdf. Accessed Nov 2020 
Adorno TW, Frenkel-Brunswik E, Levinson DJ, Sanford RN (1950) The authoritarian personality. Harper, New York

Akrami N, Ekehammar B, Araya T (2000) Classical and modern racial prejudice: a study of attitudes toward immigrants in Sweden. Eur J Soc Psychol 30(4):521-532. https://doi.org/10.1002/10990992(200007/08)30:4\%3c521::AID-EJSP5\%3e3.0.CO;2-N

Alfaro EC, Umaña-Taylor AJ, Gonzales-Backen MA, Bámaca MY, Zeiders KH (2009) Latino adolescents' academic success: The role of discrimination, academic motivation, and gender. J Adolesc 32(4):941-962

Allen Q (2012) "They think minority means lesser than": Black middle-class sons and fathers resisting microaggressions in the school. Urban Educ 48(2):171-197

Allen A, Scott LM, Lewis CW (2013) Racial microaggressions and African American and Hispanic Students in urban schools: a call for culturally affirming education. Interdiscipl J Teach Learn 3(2):117-129

Altemeyer B (1981) Right-wing authoritarianism. University of Manitoba Press, Winnipeg

Altemeyer B (1996) The authoritarian specter. Harvard University Press, Cambridge

Altemeyer B (1998) The other "authoritarian personality." Adv Exp Soc Psychol 30:47-92. https://doi. org/10.1016/S0065-2601(08)60382-2

Aronson B, Laughter J (2015) The theory and practice of culturally relevant education: a synthesis of research across content areas. Rev Educ Res 86:163-206

Bonilla-Silva E (2003) Racism without racists: color-blind racism and the persistence of racial inequality in America, 3rd edn. Rowman \& Littlefield Publishers, New York

Byrd CM (2016) Does culturally relevant teaching work? An examination from student perspectives. Student Divers. 1:1-10

Call-Cummings M, Martinez S (2017) 'It wasn't racism; it was more misunderstanding.' White teachers, Latino/a students, and racial battle fatigue. Race Ethn. Educ. 20(4):561-574

Christianakis M (2011) Hybrid texts: fifth graders, rap music, and writing. Urban Educ. 46:1131-1168

Council of Europe (2015) Recognising and preventing neo-racism. Parliamentary assembly report: committee on equality and non-discrimination (doc. 13809)

Dessel A, Rogge ME, Garlington SB (2006) Using intergroup dialogue to promote social justice and change. Soc Work 51:303-315

Duckitt J, Wagner C, du Plessis I, Birum I (2002) The psychological bases of ideology and prejudice: testing a dual process model. J Pers Soc Psychol 83:75-93

Duriez B, Soenens B (2009) The intergenerational transmission of racism: the role of right-wing authoritarianism and social dominance orientation. J Res Pers 43:906-909

Duriez B, Van Hiel A (2002) The march of modern fascism: a comparison of social dominance orientation and authoritarianism. Pers Individ Differ 32:1199-1213

Duriez B, Soenens B, Vansteenkiste M (2008) The intergenerational transmission of authoritarianism: the mediating role of parental goal promotion. J Res Pers 42:622-642

Eccles JS, Wong CA, Peck SC (2006) Ethnicity as a social context for the development of African-American adolescents. J Sch Psychol 44(5):407-426

Ekehammar B, Akrami N, Gylje M, Zakrisson I (2004) What matters most to prejudice: big five personality, social dominance orientation, or right-wing authoritarianism? Eur J Pers 18:463-482

Ensign J (2003) Including culturally relevant math in an urban school. Educ Stud 34(4):414-423

Ford DY, Moore JL, Whiting GW (2006) inating deficit orientations: Creating classrooms and curricula for gifted students from diverse cultural backgrounds. In: Constantine MG, Sue DW (eds) Addressing racism: facilitating cultural competence in mental health and educational settings. Wiley, Hoboken, NJ, pp 173-193

Gay G (2002) Preparing for culturally responsive teaching. J Teach Educ 53(2):106-116

Grantham TC, Ford DY (2003) Beyond self-concept and self-esteem: racial identity and gifted African American students. High Sch J 87:18-29

Heaven PCL, Connors JR (2001) A note on the value correlates of social dominance orientation and right-wing authoritarianism. Pers Individ Differ 31:925-930

Henfield MS, Washington AR (2012) "I want to do the right thing but what is it?": White teachers' experiences with African American students. J Negro Educ 8(2):148-161

Herandez C, Morales A, Shroyer MG (2013) The development of a model of culturally responsive science and mathematics teaching. Cult Stud Sci Educ 8:803-820 
Hodson G, Costello K (2007) Interpersonal disgust, ideological orientations, and dehumanization as predictors of intergroup attitudes. Psychol Sci 18(8):691-698. https://doi.org/10.1111/j.1467-9280. 2007.01962.x

Ladson-Billings G (1992) Culturally relevant teaching: the key to making multicultural education work. In: Grant CA (ed) Research and multicultural education. Falmer Press, London, pp 106-121

Lee J (2002) Racial and ethnic achievement gap trends: reversing the progress toward equity? Educ Res 31(1):3-12

Lee JS, Bowen NK (2006) Parent involvement, cultural capital, and the achievement gap among elementary school children. Am Educ Res J 43(2):193-218

Lee JJ, Rice C (2007) Welcome to America? International student perceptions of discrimination. High Educ 53:381-409

Levin S, Federico CM, Sidanius J, Rabinowitz JL (2002) Social dominance orientation and intergroup bias: the legitimation of favoritism for high-status groups. Pers Soc Psychol Bull 28(2):144-157. https://doi.org/10.1177/0146167202282002

Levy DJ, Heissel JA, Richeson JA, Adam EK (2016) Psychological and biological responses to racebased social stress as pathways to disparities in educational outcomes. Am Psychol 71(6):455

Lippa R, Arad S (1999) Gender, personality, and prejudice: the display of social dominance orientation and authoritarianism in interviews with college men and women. J Res Pers 33:463-493

McFarland DA (2001) Student resistance: how the formal and informal organization of classrooms facilitate everyday forms of student defiance. Am J Soc 107(3):612-678

McFarland S, Ageyev V, Abalakina M (1993) The authoritarian personality in the United States and the former Soviet Union: comparative studies. J Res Pers. https://doi.org/10.1007/978-1-4613-9180-7_ 10

Morrell E, Duncan-Andrade JM (2002) Promoting academic literacy with urban youth through engaging hip-hop culture. Engl J 91(6):88-92

Morrison KA, Robbins HH, Rose DG (2008) Operationalizing culturally relevant pedagogy: a synthesis of classroom-based research. Equity Excell Educ 41:433-452

National Center for Education Statistics (2019) The Nation's Report Card. National Assessment of Educational Progress. www.nationsreportcard.gov/mathematics/nation/achievement/?grade $=12$. Accessed Nov 2020

Neville HA (2009) Rationalizing the racial order: Racial color-blindness as a legitimizing ideology. In: Koditschek T, Cha-Jua SK, Neville HA (eds) Race struggles. University of Illinois Press, Champaign, IL, pp 115-133

Neville HA, Lilly RL, Duran G, Lee RM, Browne L (2000) Construction and initial validation of the color-blind racial attitudes scale (CoBRAS). J Couns Psychol 47:59-70. https://doi.org/10.1037/ 0022-0167.47.1.59

Neville HA, Worthington RL, Spanierman LB (2001) Race, power, and multicultural counseling psychology: understanding white privilege and color-blind racial attitudes. In: Ponterotto JG, Casas JM, Suzuki LA, Alexander CM (eds) Handbook of multicultural counseling. Sage Publications Inc, Thousand Oaks, pp 257-288

Ong AD, Burrow AL, Fuller-Rowell TE, Ja NM, Sue DW (2013) Racial microaggressions and daily wellbeing among Asian-Americans. J Couns Psychol 60:188-199

Park B, Judd CM (2005) Rethinking the link between categorization and prejudice within the social cognition perspective. Pers Soc Psychol Rev 9:108-130

Paschall KW, Gershoff ET, Kuhfeld M (2018) A two decade examination of historical race/ethnicity disparities in academic achievement by poverty status. J Youth Adolesc 47(6):1164-1177

Pascoe EA, Smart Richman L (2009) Perceived discrimination and health: a meta-analytic review. Psychol Bull 135(4):531

Plaut VC, Thomas KM, Goren MJ (2009) Is multiculturalism or color blindness better for minorities? Psychol Sci 20:444-446

Poteat VP, Spanierman LB (2012) Modern racism attitudes among White students: the role of dominance and authoritarianism and the mediating effects of racial color-blindness. J Soc Psychol 152(6):758-774

Pratto F, Sidanius J, Stallworth LM, Malle BF (1994) Social dominance orientation: a personality variable predicting social and political attitudes. J Pers Soc Psychol 67(4):741-763

Rains FV (1998) Is the benign really harmless? Deconstructing some "benign" manifestations of operationalized white privilege. In: Kincheloe JL, Steinberg SR, Rodriguez NM, Chennault RE (eds) White reign. St. Martin's, New York, pp 77-101

\section{SN Social Sciences}

A SPRINGER NATURE journal 
Reardon SF (2011) The widening academic achievement gap between the rich and the poor: new evidence and possible explanations. https://cepa.stanford.edu/sites/default/files/reardon\%20whither\% 20opportunity\%20-\%20chapter\%205.pdf. Accessed Jan 2019

Reynolds KJ, Turner JC, Haslam SA, Ryan MK (2001) The role of personality and group factors in explaining prejudice. J Exp Soc Psychol 37:427-434

Rodriguez JL, Jones EB, Pang VO, Park CD (2004) Promoting academic achievement and identity development among diverse high school students. High School J 87(3):44-53

Schnake SB, Beal DJ, Ruscher J (2006) Modern racism and intergroup bias in causal explanation. Race Gender Class 13(1/2):133-143

Sibley CG, Robertson A, Wilson MS (2006) Social dominance orientation and right-wing authoritarianism: additive and interactive effects. Polit Psychol 27(5):755-768. https://doi.org/10.1111/j.14679221.2006.00531.x

Sidanius J, Pratto F (1999) Social dominance: an intergroup theory of social hierarchy and oppression. Cambridge University Press, Cambridge

Sidanius J, Pratto F (2001) Social dominance: an intergroup theory of social hierarchy and oppression. Cambridge University Press, Cambridge, UK

Sidanius J, Pratto F, Bobo L (1994) Social dominance orientation and the political psychology of gender: a case of invariance? J Pers Soc Psychol 67:998-1011

Sidanius J, Pratto F, Bobo L (1996) Racism, conservatism, affirmative action, and intellectual sophistication: a matter of principled conservatism or group dominance? J Pers Soc Psychol 70(3):476-490. https://doi.org/10.1037/0022-3514.70.3.476

Sleeter CE (2012) Confronting the marginalization of culturally responsive pedagogy. Urban Educ 47:562-584

Solorzano D, Ceja M, Yosso T (2000) Critical race theory, racial microaggressions, and campus racial climate: the experiences of African-American college students. J Negro Educ 69:60-73

Stenner K (2009) Three kinds of “conservatism.” Psychol Inq 20:142-159. https://doi.org/10.1080/10478 400903028615

Stone S, Han M (2005) Perceived school environments, perceived discrimination, and school performance among children of Mexican immigrants. Child Youth Serv Rev 27(1):51-66

Stovall D (2006) We can relate: Hip-hop culture, critical pedagogy, and the secondary classroom. Urban Educ 41:585-602

Sue DW, Capodilupo CM, Torino GC, Bucceri JM, Holder AM, Nadal KL, Esquilin M (2007) Racial microaggressions in everyday life: implications for clinical practice. Am Psychol 62(4):271-286

Sue DW, Capodilupo CM, Holder AMB (2008) Racial microaggressions in the life experience of Black Americans. Prof Psychol Res Pract 39:329-336

Sue DW, Lin AI, Torino GC, Capodilupo CM, Rivera DP (2009) Racial microaggressions and difficult dialogues on race in the classroom. Cultur Divers Ethnic Minor Psychol 15(2):183-190

Thompson CE, Neville HA (1999) Racism, mental health, and mental health practice. Counsel Psychol 27:155-223

Torres L, Driscoll MW, Burrow AL (2010) Racial microaggressions and psychological functioning among highly achieving African-Americans: a mixed methods approach. J. Soc. Clin. Psychol. 29(10):1074-1099

Torres-Harding S, Turner T (2015) Assessing racial microaggression distress in a diverse sample. Eval Health Prof 38(4):464-490

Van Hiel A, Mervielde I (2002) Explaining conservative beliefs and political preferences: a comparison of social dominance orientation and authoritarianism. J Appl Soc Psychol 32(5):965-976. https:// doi.org/10.1111/j.1559-1816.2002.tb00250.x

White E (2012) Whiteness and teacher education. Routledge, New York

Whitley BE (1999) Right-wing authoritarianism, social dominance orientation, and prejudice. J Pers Soc Psychol 77:126-134. https://doi.org/10.1037/0022-3514.77.1.126

Whitley BE Jr, Ægisdottir S (2000) The gender belief system, authoritarianism, social dominance orientation, and heterosexuals' attitudes toward lesbians and gay men. Sex Roles 42:947-967

Whitley BE, Lee SE (2000) Relationships of authoritarianism and related constructs to attitudes toward homosexuality. J Appl Soc Psychol 30:144-170

Williams A (2011) A call for change: narrowing the achievement gap between white and minority students. Clear House 84(2):65-71

Wong CA, Eccles JS, Sameroff A (2003) The influence of ethnic discrimination and ethnic identification on African American adolescents' school and socioemotional adjustment. J Pers 7(6):1197-1232 